\title{
Period poverty and mental health implications among college-aged women in the United States
}

\author{
Lauren F. Cardoso', Anna M. Scolese ${ }^{2}$, Alzahra Hamidaddin ${ }^{2}$ and Jhumka Gupta ${ }^{2 *}$
}

\begin{abstract}
Background: The purpose of this study is to examine the frequency of "period poverty," or not being able to afford sanitary products, among university students, and associations with poor mental health.

Methods: An online survey was conducted with a nationally-drawn sample $(N=471)$ of college-attending women to assess the association between period poverty and depression. Period poverty was measured via two questions designed for this study; depression was measured with the standard PHQ-9. Multivariable logistic regression was utilized for analysis.

Results: Among our sample, $14.2 \%$ of women had experienced period poverty ever in the past-year; an additional $10 \%$ experienced it every month. Compared to those who had never experienced period poverty, adjusted analysis revealed that women with monthly past-year period poverty were the most likely to report moderate/severe depression $(A O R=2.34,95 \% \mathrm{Cl} 1.09-4.99)$, followed by those who had experienced it ever in the past year $(A O R=1.83,95 \%$ $\mathrm{Cl}, 0.99-3.38)$.

Conclusion: Many young women cannot afford menstrual health products to meet their monthly needs, and this may impact their mental well-being. Improved access to affordable menstrual products is needed to support these young women.
\end{abstract}

Keywords: Menstruation, Period poverty, Menstrual health, Sanitary products, Mental health

\section{Background}

It is well established that meeting one's basic needsfood, water, shelter-is the necessary foundation for health and well-being. Research indicates that the inability to meet these needs can affect individuals' mental health $[1,2]$. For instance, in a study of 2,870 mothers across 18 cities in the U.S., prevalence of major depression or generalized anxiety disorder increased with severity of food insecurity after controlling for factors

\footnotetext{
*Correspondence: jgupta4@gmu.edu

2 Department of Global and Community Health, College of Health and Human Services, George Mason University, 4400 University Dr., Fairfax, VA 22030, USA

Full list of author information is available at the end of the article
}

such as income and past-year eviction [3]. This suggests that unmet basic needs, such as food and nutrition, can impact mental health above and beyond other hardships.

Menstrual hygiene is also considered a basic need, yet very little research has examined how unmet menstrual hygiene needs may impact mental health. Only recently, and after much effort by a small group of researchers and advocates, has menstrual health and hygiene been recognized as a pressing public health issue [4]. The unmet menstrual health needs of women and girls globally is vast, and includes the inability to access safe, clean facilities and affordable menstrual products [5]. The World Bank estimates that 500 million women and girls globally lack access to adequate facilities for menstrual hygiene management [6]. They also lack access to menstrual 
products. For example, over $80 \%$ of menstruating women and girls in Bangladesh use inadequate materials (e.g. old cloth) instead of hygienic products such as pads or tampons [7]. These unmet needs have important educational consequences for the lives of women and girls. In schools where girls lack access to hygienic facilities, menstruation can contribute to absenteeism or leaving school completely [8].

While the overwhelming majority of evidence and advocacy on unmet menstrual hygiene needs center on the experiences of women and girls in low- and middleincome countries, new research suggests that the experience of "period poverty," or not being able to afford menstrual products, may be a common concern for lowincome women in high-income countries. In a recent study with 183 low-income women in St. Louis, Missouri, $64 \%$ of participants reported being unable to afford menstrual products in the previous year [5]. One-third of women $(n=61)$ reported using other products as a result, including rags, toilet paper, and their children's diapers. Aside from this study, public health research, and particularly epidemiologic data, on the experience of "period poverty" is scarce. Furthermore, even less is known about the mental health implications of period poverty. Given prior research documenting associations between other unmet needs and mental health, and the added shame and stigma associated with menstruation, an assessment of period poverty and how it relates to mental health is warranted.

An investigation of potential associations between period poverty and mental health is particularly important among college students. According to the 2018 American College Health Assessment, 63\% of college students felt "overwhelming anxiety" in the previous 12 months. More than 1 in 10 (12.7\%) had seriously considered suicide in that same time period [9]. Additionally, given that recent reports indicate that $35-50 \%$ of undergraduates may be food insecure, high levels of period poverty may also be present and thus research is warranted [10].

The current study aims to fill this critical gap by quantitatively examining, among a nationally drawn sample of young women enrolled in undergraduate education, (1) the frequency of self-reported experiences of past-year period poverty, and (2) the associations between past year period poverty and mental health.

\section{Methods}

This study is part of a larger survey on women's menstrual health, symptoms suggestive of endometriosis, and stigma. The online survey was conducted in April 2019 among a nationally-drawn sample of undergraduate women.
The sample was selected with the assistance of Qualtrics, a research firm specializing in online surveys and recruitment. Potential respondents likely to meet the inclusion criteria received an email introducing the study and its procedures. Interested participants read the written consent form online and provided informed consent before completing the 20-minute, online survey. The study received Institutional Review Board approval from George Mason University (\# 1159779-6).

Participants met eligibility criteria if they were aged 18-24, reported a female sex at birth, and enrolled as a student in undergraduate education. A total of 515 respondents completed the survey. For this analysis, 471 respondents were included. Those who have never had a period $(n=4)$ or who hadn't had a period in the past-year $(\mathrm{n}=27)$ were excluded from analysis.

Period poverty was assessed by asking two questions, first: "In the past 12 months have you struggled to afford menstrual products (such as sanitary pads or tampons)?" Those who answered "yes" (vs. "no") were asked a follow-up question, "Do you struggle to afford menstrual products every month?". Responses were used to construct a three-level categorical variable: participants who reported experiencing period poverty every month; participants who reported experiencing period poverty in the past year, but not on a monthly basis; and those who reported never experiencing period poverty.

Respondents who reported any past-year period poverty or period poverty every month were also asked, "have you done any of the following because you did not have enough money to purchase menstrual products?" and could select any of the following options: Used other products (e.g., toilet paper, fabric) as menstrual products, Borrowed menstrual products (e.g., from friends, coworkers, strangers), Left a menstrual product in too long, Had to go without menstrual products, I have always had enough money to purchase menstrual products, Other. These measures were developed based on previous menstrual health research [5]. An additional file provides these questionnaire items (see Additional file 1).

The Patient Health Questionnaire (PHQ-9), a 9-item scale that has been well-validated and widely used with a variety of populations including young people, was used to assess depression [11]. Respondents were asked, "Over the past 2 weeks, how often have you been bothered by the following problems?" Nine "problems" were listed (for example, "poor appetite or overeating") and responses included "not at all," "several days," "more than half the days," "nearly every day." Respondents received a total score ranging from 0 to 27. A dichotomous variable was constructed: those who had none or mild depression (scores 0-9), and those who had moderate to severe depression (scores 10-27). 
Previous health research among college students informed our demographic variables [12]. Respondents were asked their age (numeric responses), relationship status (not in a relationship, in a relationship but not cohabitating, in a relationship and cohabitating), selfreported health status (excellent, very good, good, fair, poor, don't know), where they live (on- or off-campus), and enrollment status (full- or part-time). They were also asked their race (White; Black; Hispanic or Latino/a; Asian or Pacific Islander; American Indian, Native Alaskan, Native Hawaiian; Biracial or Multiracial; Other), though this variable was collapsed to 4 categories (White, Black, Hispanic or Latino/a, Other). Country of origin (259 response options) was constructed as a dichotomous variable, differentiating between individuals born in the United States and individuals born elsewhere. Sexual orientation (asexual, bisexual, gay, lesbian, pansexual, queer, questioning, same gender loving, straight/heterosexual, other) was collapsed to a 2-category variable (heterosexual/straight, other). Finally, two variables, mother's education and father's education (response options: less than high school completed, high school diploma or equivalent, some college, vocational or trade school, bachelor's degree, master's degree, professional degree, doctorate, don't know, not applicable), were combined to create a "first generation" college student variable. Respondents who did not have a parent with a college degree were considered "first generation"; respondents with at least one parent with a college degree or higher were not considered "first generation" [13].

Frequencies and means (where appropriate) were examined for all variables. Bivariate analysis using Pearson's $\mathrm{X} 2$, t-tests, and one-way analysis of variance assessed the relationship between demographic variables and period poverty, and demographic variables and depression. Logistic regressions assessed the relationship between period poverty and depression, controlling for sociodemographic variables. To preserve power, some covariates were dichotomized for regression analyses. Significance levels were set at 0.05. All analysis was conducted in Stata v14.1.

\section{Results}

The mean age of our sample $(\mathrm{N}=471)$ was 20.6 years. Two-thirds of our respondents reported their race as White (65.6\%), while 16.8\% reported being Black, $11.3 \%$ Hispanic/Latina, and $6.4 \%$ were another race. The majority of the sample (92.6\%) was born in the US; slightly over four in ten $(43.3 \%)$ were first generation college students. Sixty-five percent reported their sexual orientation as "straight/heterosexual." Around 3 out of 4 respondents were enrolled full-time (76.7\%) and lived off campus (79.0\%). In terms of relationship status, $46.3 \%$ reported being single, $35.9 \%$ were in a relationship but not cohabitating, and $17.8 \%$ were in a relationship and cohabitating. One in five respondents $(20.3 \%)$ rated their health as "excellent," while 1 in 10 (9.4\%) rated it as "fair/poor."

Among our sample, $14.2 \%$ of women had experienced period poverty ever in the past-year; an additional $10.0 \%$ experienced it every month. As a result, women coped with their menstrual product needs in a variety of ways. The most frequently mentioned coping methods included borrowing products $(72.8 \%)$, using other materials in lieu of menstrual products $(52.6 \%)$, using pads or tampons for longer than suggested (48.3\%), and going without any products $(26.3 \%)$. Experiencing period poverty differed significantly by race $(p=0.038)$. Past-year period poverty was most frequently reported by Latina women (24.5\%), followed by Black women (19\%), White women (11.7\%), and women of another race (10.0\%). Experiencing period poverty every month was also most frequently reported by Latina women $(17.0 \%)$, followed by women of another race (13.3\%), White women (9.1\%), and Black women (7.6\%). Respondents who were born outside of the US $(p=0.003)$ also reported higher levels of period poverty (past-year: $20.0 \%$, every month $25.7 \%$ ) than young women born in the U.S. (past year: 13.8\%, every month: 8.7\%). Experiencing period poverty also varied significantly by family education $(p=0.005)$. One in five first generation college students (20.1\%) reported past-year period poverty, an additional $10.3 \%$ reported monthly period poverty. One in ten non-first generation students experienced past-year (9.7\%) and monthly (9.7\%) period poverty. No significant difference was observed for other sociodemographic variables (displayed in Table 1 below).

Just under half $(48.4 \%)$ the sample reported moderate or severe depression. Depression severity only differed significantly by sexual orientation $(p<0.001)$, such that respondents who are not straight (vs. those who are) reported more severe depression, and by health status $(p<0.001)$. Those who had the lowest self-rated health reported the most severe depression.

Among women who reported experiencing period poverty every month, $68.1 \%$ reported symptoms consistent with moderate or severe depression, compared to $61.2 \%$ of women who had experienced any period poverty, and $43.4 \%$ of those who had not experienced period poverty. Unadjusted analyses in Table 2 (below) showed a significant relationship between any past-year period poverty and moderate/severe depression $(\mathrm{OR}=2.05,95 \%$ CI 1.20-3.50) and between experiencing period poverty every month and moderate/severe depression $(\mathrm{OR}=2.78$, 95\% CI 1.45-5.31). These relationships remained significant in the adjusted analyses. In comparison to participants who reported no period poverty, young women who had experienced any past-year period poverty or 
Table 1 Bivariate associations between demographics and past-year period poverty, and depression

\begin{tabular}{|c|c|c|c|c|c|c|c|c|}
\hline $\begin{array}{l}\text { Demographic } \\
\text { variables }\end{array}$ & Sample N(\%) & $\begin{array}{l}\text { No period } \\
\text { poverty } n \\
(\%)^{b}\end{array}$ & $\begin{array}{l}\text { Past-year any } \\
\text { period poverty } \\
\mathrm{n}(\%)^{\mathbf{b}}\end{array}$ & $\begin{array}{l}\text { Past-year monthly } \\
\text { period poverty } \\
\mathrm{N}(\%)^{\mathbf{b}}\end{array}$ & $P$ value & $\begin{array}{l}\text { No/minimal } \\
\text { depression }^{b}\end{array}$ & $\begin{array}{l}\text { Moderate/ } \\
\text { severe } \\
\text { depression }\end{array}$ & $P$ value \\
\hline Total sample (n [\%]) & $471(100.0)$ & $357(75.8)$ & $67(14.2)$ & $47(10.0)$ & & $243(51.6)$ & $228(48.4)$ & \\
\hline Age $($ mean $=X)$ & 20.6 & 20.5 & 20.5 & 20.5 & 0.891 & 20.6 & 20.5 & 0.503 \\
\hline \multicolumn{9}{|l|}{ Race } \\
\hline White & 309 (65.6) & 79.3 & 11.7 & 9.1 & 0.038 & 53.7 & 46.3 & 0.404 \\
\hline Black & $79(16.8)$ & 73.4 & 19.0 & 7.6 & & 46.8 & 53.2 & \\
\hline Latino/a & $53(11.3)$ & 58.5 & 24.5 & 17.0 & & 52.8 & 47.2 & \\
\hline Other & $30(6.4)$ & 76.7 & 10.0 & 13.3 & & 40.0 & 60.0 & \\
\hline \multicolumn{9}{|l|}{ Country of origin } \\
\hline US & $436(92.6)$ & 77.5 & 13.8 & 8.7 & 0.002 & 52.8 & 47.3 & 0.075 \\
\hline Other & $35(7.4)$ & 54.3 & 20.0 & 25.7 & & 37.1 & 62.9 & \\
\hline \multicolumn{9}{|l|}{ Sexual orientation } \\
\hline $\begin{array}{l}\text { Heterosexual/ } \\
\text { straight }\end{array}$ & $306(65.0)$ & 78.1 & 13.4 & 8.5 & 0.228 & 60.1 & 39.9 & $<0.001$ \\
\hline Other & $165(35.0)$ & 71.5 & 15.8 & 12.7 & & 35.8 & 64.2 & \\
\hline \multicolumn{9}{|c|}{ First generation college } \\
\hline Yes & $204(43.3)$ & 69.6 & 20.1 & 10.3 & 0.005 & 49.0 & 51.0 & 0.329 \\
\hline No & $267(56.7)$ & 80.5 & 9.7 & 9.7 & & 53.6 & 46.4 & \\
\hline \multicolumn{9}{|l|}{ Enrollment status } \\
\hline Full-time & $361(76.7)$ & 77.0 & 12.7 & 10.3 & 0.246 & 52.4 & 47.7 & 0.549 \\
\hline Part-time & $110(23.3)$ & 71.8 & 19.1 & 9.1 & & 49.1 & 50.9 & \\
\hline \multicolumn{9}{|l|}{ Living situation } \\
\hline Off campus & $325(79.0)$ & 74.8 & 13.9 & 11.4 & 0.312 & 49.5 & 50.5 & 0.183 \\
\hline On campus & $146(31.0)$ & 78.1 & 15.1 & 6.9 & & 56.2 & 43.8 & \\
\hline \multicolumn{9}{|l|}{ Relationship status } \\
\hline Single & $218(46.3)$ & 78.0 & 11.9 & 10.1 & 0.107 & 54.1 & 45.9 & 0.383 \\
\hline $\begin{array}{l}\text { Relationship, not } \\
\text { cohabitating }\end{array}$ & $169(35.9)$ & 78.1 & 14.8 & 7.1 & & 51.2 & 48.5 & \\
\hline $\begin{array}{l}\text { Relationship, } \\
\text { cohabitating }\end{array}$ & $84(17.8)$ & 65.5 & 19.1 & 15.5 & & 45.2 & 54.8 & \\
\hline \multicolumn{9}{|c|}{ Self-rated Health status } \\
\hline Excellent & $87(20.3)$ & 80.5 & 8.1 & 11.5 & 0.184 & 57.5 & 42.5 & $<0.001$ \\
\hline Very good & 169 (39.5) & 76.9 & 16.0 & 7.1 & & 61.5 & 38.5 & \\
\hline Good & $132(30.8)$ & 81.8 & 9.9 & 8.3 & & 45.5 & 54.6 & \\
\hline Fair/poor & $40(9.4)$ & 67.5 & 22.5 & 10.0 & & 25.0 & 75.0 & \\
\hline
\end{tabular}

a Column percentages

${ }^{b}$ Row percentages

Table 2 Unadjusted and adjusted logistic regressions for associations between past-year and past-month period poverty and depression $(\mathrm{N}=471)$

\begin{tabular}{|c|c|c|c|c|}
\hline Experience of period poverty & $\begin{array}{l}\text { None/minimal } \\
\text { depression (\%) }\end{array}$ & $\begin{array}{l}\text { Moderate/severe } \\
\text { depression (\%) }\end{array}$ & Odds ratio $(95 \% \mathrm{Cl})$ & $\begin{array}{l}\text { Adjusted } \\
\text { odds ratio } \\
(95 \% \mathrm{Cl})\end{array}$ \\
\hline No period poverty & 56.6 & 43.4 & Referent & Referent \\
\hline Past-year any period poverty & 38.8 & 61.2 & $2.05(1.20-3.50)$ & $\begin{array}{l}1.83(0 / .99- \\
3.38)\end{array}$ \\
\hline Past-year monthly period poverty & 31.9 & 68.1 & $2.78(1.45-5.31)$ & $2.34(1.09-4.99$ \\
\hline
\end{tabular}

AORs controlling for age, race, first generation student, US born, living situation, relationship status, enrollment, sexual orientation, self-rated health status 
monthly period poverty were significantly more likely to report moderate/severe depression $(\mathrm{AOR}=1.83,95 \% \mathrm{CI}$ $0.99-3.38 ; \mathrm{AOR}=2.34,95 \%$ CI 1.09-4.99, respectively).

\section{Post-hoc analysis}

We conducted additional analysis to examine potential impacts of a prior mental health diagnosis on the association of interest in our study. Specifically, we ran an additional model where we accounted for prior selfreported mental health diagnosis (i.e., the respondent was asked if they had ever been told by a doctor, nurse, or other health professional if they had a depressive disorder, including depression, major depression, dysthymia, or minor depression). In this post-hoc analysis, the adjusted ORs were slightly attenuated and remained significant for the association between both any past-year period poverty and depressive symptoms $(\mathrm{OR}=2.02$, 95\% CI 1.13-3.62) and monthly past-year period poverty and depressive symptoms ( $\mathrm{OR}=2.47,95 \% \mathrm{CI} 1.23-4.96)$. Future research is needed to examine any potential role that timing of diagnosis, lack of diagnosis, and medication may have on the association of interest.

\section{Discussion}

In this nationally-drawn sample of college attending women in the United States, $14.2 \%$ had ever experienced period poverty in the past year; an additional $10.0 \%$ had experienced it every month. This is the first study to quantify unmet menstrual product needs among this population. This study also sought to assess the relationship between period poverty and depression. Findings revealed that period poverty was significantly associated with depression on a gradient. Compared to those who had never experienced period poverty, women who had experienced period poverty every month reported the most severe depression, followed by those who had ever experienced period poverty in the past year.

To our knowledge, there are no other studies that have examined the mental health impacts of period poverty, thus making comparisons difficult. However, our findings are broadly consistent with other research documenting an association between unmet basic needs and an elevated likelihood of poor mental health. For example, food insecurity has been found to be associated with depression among adults and depression, suicidal ideation, and anxiety among young adults and adolescents [14-16]. Similarly, people experiencing housing insecurity are more likely to report depression and anxiety than those who are stably housed $[17,18]$. Notably, these studies collectively indicate that these unmet needs uniquely contribute to mental health, above and beyond the effects of income or wealth. The same may be true of unmet menstrual health needs, particularly given the shame and stigma associated with menstruation generally [19-21].

This study has several limitations. Income level is difficult to measure among college students via self-report, as discussed in existing research on food insecurity among university students [22]. Thus, this was not included as a covariate. Therefore, we could not test if period poverty was associated with depression independent of economic deprivation. Future research would be strengthened with the inclusion of appropriate economic measures, including food security, for this population. In addition, the sample was not probability-based and we do not have data on those who declined participation. Responses and findings are only generalizable to the demographics and experiences within this study. Finally, there is no standard way to assess period poverty. Although our measures were consistent with previous qualitative and quantitative research, more research is needed to validate our approach. Future research is also needed with broader populations of menstruators, including transgender and non-binary populations.

These limitations notwithstanding, this study is among the first to quantify period poverty and to examine its association with depression, and has implications for research and programming. Period poverty has not been definitively defined in academic spaces, and thus further scale development research is warranted.

Regarding programming and policy, addressing the mental health issues of college students is of particular concern given the high prevalence of stress, anxiety, and depression experienced by this population [9]. College administrators are addressing the issue by adding more comprehensive mental health services, but they should also examine the importance of unmet needs. Specifically, they should assess how period poverty may be contributing to the mental health issues among young women and consider making products more accessible. Some universities have such efforts underway-offering free menstrual products to students - and in some places in conjunction with efforts to reduce food insecurity.

More broadly, city- and state-level policy efforts to reduce the cost of menstrual products and increase their accessibility among vulnerable populations are gaining momentum. For example, as of 2016 New York City provides free menstrual products in public schools, homeless shelters, and prisons [23]. Similarly, starting in the fall of 2019 , Boston began providing free menstrual products in public middle and high schools [24]. Several states have successfully repealed the "tampon tax" or the tax levied on menstrual products in states that consider them "luxury items" [25]. There have been added calls from advocates to remove other structural barriers to accessing menstrual products, such as requiring Medicaid and 
Supplemental Nutrition Assistance Program to cover menstrual products [26].

\section{Conclusion}

Though preliminary, current study findings suggest that many young women cannot afford menstrual health products to meet their monthly needs, and this may impact their mental well-being. Improved access to affordable menstrual products is needed to support these young women. With additional research to help inform how period poverty impacts college students, there is tremendous opportunity to help address this critical, yet under-addressed issue.

\section{Supplementary Information}

The online version contains supplementary material available at https://doi. org/10.1186/s12905-020-01149-5.

Additional file 1 Period Poverty Questionnaire Items. This document includes the three questionnaire items related to period poverty that were used to assess period poverty prevalence in our study population.

\section{Abbreviations}

AOR: Adjusted odds ratio; Cl: Confidence interval; OR: Odds ratio; PHQ-9: The Patient Health Questionnaire.

\section{Acknowledgements}

We would also like to acknowledge Jennifer Weiss-Wolf for her helpful insights on current policy efforts to address period poverty.

\section{Authors' contributions}

LC led the writing of the manuscript, data analysis and conceptualized the study. AS and $\mathrm{AH}$ assisted with writing and interpretation of findings. JG co-led the conceptualization and design of the study. All authors read and approved the final manuscript.

\section{Funding}

We would like to acknowledge our funders, the Endometriosis Foundation of America (EndoFound) (Grant \#:223049, PI: Dr. Jhumka Gupta). EndoFound had no role in study design, analysis, or writing.

\section{Availability of data and materials}

The datasets used and/or analyzed during the current study are available from the corresponding author on reasonable request.

\section{Ethics approval and consent to participate}

The study received Institutional Review Board approval from George Mason University (\# 1159779-6). Written informed consent was obtained from all participants.

\section{Consent for publication}

Not applicable.

\section{Competing interests}

The authors declare that they have no competing interests.

\section{Author details}

${ }^{1}$ School of Social Policy and Practice, University of Pennsylvania, Philadelphia, PA, USA. ${ }^{2}$ Department of Global and Community Health, College of Health and Human Services, George Mason University, 4400 University Dr., Fairfax, VA 22030, USA
Received: 29 July 2020 Accepted: 11 December 2020

Published online: 06 January 2021

\section{References}

1. Gundersen C, Ziliak JP. Food insecurity and health outcomes. Health Aff. 2015;34(11):1830-9.

2. Singh A, Daniel L, Baker E, Bentley R. Housing disadvantage and poor mental health: a systematic review. Am J Prev Med. 2019;57(2):262-72.

3. Whitaker RC, Phillips SM, Orzol SM. Food insecurity and the risks of depression and anxiety in mothers and behavior problems in their preschool-aged children. Pediatrics. 2006;118(3):1242.

4. Sommer M, Hirsch JS, Nathanson C, Parker RG. Comfortably, safely, and without shame: defining menstrual hygiene management as a public health issue. Am J Public Health. 2015;105(7):1302.

5. Kuhlmann AS, Bergquist EP, Danjoint D, Wall LL. Unmet menstrual hygiene needs among low-income women. Obstet Gynecol. 2019;133(2):238-44

6. The World Bank. Menstrual hygiene management enables women and girls to reach their full potential. 2018. https://www.worldbank.org/en/ news/feature/2018/05/25/menstrual-hygiene-management. Accessed 29 Jan 2020.

7. International Centre for Diarrheal Diseases Research, WaterAid Bangladesh. Bangladesh National Hygiene Baseline Survey: Preliminary Report. Dhaka: International Centre for Diarrheal Diseases Research; 2014. https:// www.ircwash.org/sites/default/files/bnhbs.pdf. Accessed 29 Jan 2020.

8. Tegegne T, Sisay M. Menstrual hygiene management and school absenteeism among female adolescent students in Northeast Ethiopia. BMC Public Health. 2014;14(1):1118.

9. American College Health Association. Spring 2018 reference group executive summary. Silver Spring, MD: American College Health Association; 2018. https://www.acha.org/documents/ncha/NCHAll_Sprin g_2018_Reference_Group_Executive_Summary.pdf. Accessed 29 Jan 2020

10. Goldrick-Rab S, Baker-Smith C, Coca V, Looker E, Williams T. College and university basic needs insecurity: a national \#RealCollege survey report. Philadelphia, PA: The HOPE Center; 2019. https://hope4college.com/ wp-content/uploads/2019/04/HOPE_realcollege_National_report_digit al.pdf. Accessed 29 Jan 2020.

11. Richardson LP, MCCauley E, Grossman DC, McCarty C, Richards J, Russo JE, et al. Evaluation of the Patient Health Questionnaire (PHQ-9) for detecting major depression among adolescents. Pediatrics. 2010;126(6):1117-23.

12. American College Health Association. National college health assessment. Silver Spring, MD: American College Health Association; 2011. https://www.acha.org/documents/ncha/ACHA-NCHA_Ilc_Web_Surve y_2011_SAMPLE.pdf. Accessed 29 Jan 2020.

13. Cataldi EF, Bennet CT, Chen X. First-generation students: college access, persistence, and postbachelor's outcomes. Washington, DC: National Center for Education Statistics; 2018. https://nces.ed.gov/pubs2 018/2018421.pdf. Accessed 29 Jan 2020.

14. Heflin CM, Siefert K, Williams DR. Food insufficiency and women's mental health: Findings from a 3-year panel of welfare recipients. Soc Sci Med. 2005;61(9):1971-82

15. Pryor L, Lioret S, Van der Waerden J, Fombonne É, Falissard B, Melchior M. Food insecurity and mental health problems among a community sample of young adults. Soc Psychiatry Psychiatr Epidemiol. 2016;51(8):1073-81.

16. McLaughlin KA, Green JG, Alegría M, Costello JE, Gruber MJ, Sampson NA, et al. Food insecurity and mental disorders in a national sample of U.S. adolescents. J Am Acad Child Adolesc Psychiatry. 2012;51(12):1293-303.

17. Stahre M, VanEenwyk J, Siegel P, Njai R. Housing insecurity and the association with health outcomes and unhealthy behaviors. Prev Chronic Dis. 2015;12:1-6.

18. Burgard SA, Seefeldt KS, Zelner S. Housing instability and health: findings from the Michigan recession and recovery study. Soc Sci Med. 2012;75(12):2215-24

19. Schooler D, Ward LM, Merriwether A, Caruthers AS. Cycles of shame: menstrual shame, body shame, and sexual decision-making. J Sex Res. 2005:42(4):324-34. 
20. Lee J. Bodies at menarche: stories of shame, concealment, and sexual maturation. Sex Roles. 2008;60(9):615-27.

21. Laws S. Issues of blood: the politics of menstruation. Basingstoke, Hampshire: Macmillan; 1990.

22. Chaparro PM, Zaghloul SS, Holck P, Dobbs J. Food insecurity prevalence among college students at the University of Hawai'i at Mānoa. Public Health Nutr. 2009;12(11):2097-103.

23. The Official Website of the City of New York. Mayor de Blasio signs legislation increasing access to feminine hygiene products for students. 2016. http://www1.nyc.gov/office-of-the-mayor/news/611-16/mayor-de-blas o-signs-legislation-increasing-access-feminine-hygiene-products-stude nts. Accessed 29 Jan 2020

24. The Boston Globe. Kempe Y. Walsh announces program to provide free menstrual products in Boston Schools, but some say it doesn't go far enough. 2019. https://www.bostonglobe.com/metro/2019/06/17/walsh -announces-program-provide-free-menstrual-products-boston-schoo Is-but-some-say-doesn-far-enough/AvODOuHAGSJdt66OKXoBGK/story html. Accessed 29 Jan 2020.

25. Period Equity. Food or tampons? No one should have to choose. https:// www.periodequity.org/issues. Accessed 29 Jan 2020.

26. Menstrual Equity for All Act of 2019. H.R., 1882, 116th Cong. (2019).

\section{Publisher's Note}

Springer Nature remains neutral with regard to jurisdictional claims in published maps and institutional affiliations.
Ready to submit your research? Choose BMC and benefit from:

- fast, convenient online submission

- thorough peer review by experienced researchers in your field

- rapid publication on acceptance

- support for research data, including large and complex data types

- gold Open Access which fosters wider collaboration and increased citations

- maximum visibility for your research: over 100M website views per year

At BMC, research is always in progress.

Learn more biomedcentral.com/submissions 